\title{
VARIABLE VALVE TIMING SCHEDULING IN A 4-STROKE INTERNAL COMBUSTION CYLINDER UTILIZING ARTIFICIAL NEURAL NETWORKS
}

\author{
Sepehr Bapiri', Omid Chaghaneh², Hossein Ghomashi ${ }^{2}$ \\ 1 Faculty of Mechanical Engineering, Istanbul Technical University, Istanbul, Turkey, e-mail: bapiris@itu.edu.tr \\ 2 Department of Mechanical Engineering, South Tehran Branch, Islamic Azad University, Tehran, Iran, e-mail: \\ st_o_chaghaneh@azad.ac.ir, h_ghomashi@azad.ac.ir
}

Received: 2017.05.15

Accepted: 2017.08.01

Published: 2017.09.03

\begin{abstract}
The apparently simple structure of a four-stroke internal combustion cylinder belies the complicated problem of optimizing valve operation in response to a change in crankshaft rotation speed. The objective of this study was to determine the cylinder pressure for valve event angles in order to determine the optimal strategy for the timing of valve events when independently-actuated valves are available. In this work, an artificial neural network is applied to create a prediction matrix to anticipate the best variable valve timing approach according to rotation speed.
\end{abstract}

Keywords: Variable valve timing, cylinder pressure, independent valve operation, artificial neural network.

\section{INTRODUCTION AND PROBLEM STATEMENT}

In a conventional four-stroke engine with or without spark ignition, designers must align the burn phase with the maximum pressure event, as demonstrated in a model by S. Kuo [17]. This timing is invariant, but inlet valve lifting at the first stroke and exhaust valve opening at the last stroke can only be prevised under optimal operation for a specific crankshaft rotation speed with traditional camshaft coupling. The problem emerges when the speed changes, as the load or fuel rail pressure conditions then change so that the valves must close or open earlier or later to prevent the fuel gas inlet or emission outlet from interfering with the other strokes.

Before defining the problem, the valve events should be explained. Theoretically, suction and exhaust events should occur at the top and bottom of the piston at dead centre, but in practice, these events occur either earlier or later. Figure 1 shows a common representation of the cylinder events according to crank angle in a timing diagram.
Correct timing is essential to engine efficiency. Issues such as valve inertia and path reluctance against the flow prevent the timing from being ideal at a given moment; thus, the practical engine must contain lead-lag events such as inlet valve opening (IVO). These events are set to occur at $-10^{\circ}$ to $25^{\circ}$ for the top dead center (TDC). Inlet valve closing (IVC) occurs at $-25^{\circ}$ to $50^{\circ}$ around the bottom dead center (BDC) and exhaust valve opening (EVO) at $-30^{\circ}$ to $50^{\circ}$ at the BDC. Exhaust valve closing (EVC) occurs at $-10^{\circ}$ to $15^{\circ}$ around the TDC and fluid motion is even more tightly limited within these spans. This is where the problem occurs.

In an article by Joonsup Han [12], the authors found that if the exhaust valve opens too late, the burned gas volume inside the cylinder will increase and the pressure will decrease. This leads to loss of work that is needed to push the fluid out. If this valve opens too early, some of the energy of ignition will leach out. Furthermore, if the exhaust valve closes too late, some of the waste may be pulled back in and occupy space, negatively affecting combustion. If the intake valve 


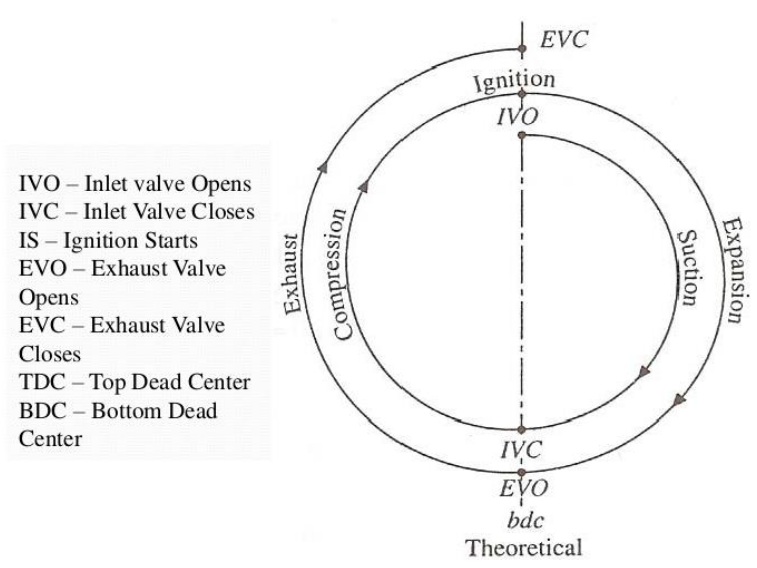

Fig. 1. Valve diagrams and Event definition

opens too early, the expanding emissions create excess pressure which may find its way to the fuel rail and contaminate the fuel supply. If the input valve closes too late, the maximum pressure and temperature conditions suitable for ignition may be lost. The valve motions are often triggered by the camshaft, which rotates at half the crankshaft speed; thus, it is not possible to manipulate events into a more optimal timing when the speed alters.

In order to resolve these issues, a fully-flexible valve actuation system is required to continuously vary the valve opening and closing times according to the crank angle. Such a design could maintain the optimum timing at all spins. A number of variable valve timing systems which have already been introduced or are under development, are mentioned in a paper by Carrie M. Hall [5]. Earlier systems discussed in S. M. Rabia's paper [18] rely only on discrete steps applied to the proportion between the crankshaft and camshaft, but such a design cannot be completely effective because a shift in one will have an effect on the other events. For instance, if the IVC lags by $10^{\circ}$, the IVO, EVC and EVO will also experience a delay. The current study does not discuss ways of devising variable valve timing (VVT) systems, but studies the effect of fully-variable VVT on cylinder output to find a way to supervise those events with a trained prediction matrix.

\section{LITERATURE REVIEW}

Attempts have been made to devise methods of developing and applying VVT to engine performance, but most are executed by gathering practical data without trying to identify the plan and its mathematical models and others are simply application techniques. One early study by Luria D. [15] concluded that enforcing variations in the IVC could be advantageous. Fontana G. [9] utilized detailed computer simulations of physical traits to show that, in both single- and multi-cylinder engines, late IVC (LIVC) can diminish the pressure tension caused by manifold pulsations. If some of the new charge is pumped backward, a more uniform residual gas distribution between the cylinders will be achieved. In one article, Tuttle J. [20] reported that LIVC will not increase fuel consumption. This is contrary to the results reported in Wu C's paper [21] in which LIVC caused a four-cylinder four-stroke engine to improve full-load engine efficiency by $11 \%$.

Although late EVO (LEVO) decreases the exhaust gas pressure and requires work for pumping out, Hara S. [11] found that this could improve volumetric efficiency if the exhaust gas is fully pumped out by the piston, because no residual gas will remain inside.

Kang J. Mo [13] equipped a diesel engine with a pneumatic inlet-valve controller which acts using a nonlinear mean value model under wide-gap dynamic conditions, and the results show some improvement. Benson R. S. [1] demonstrated that a four-cylinder four-stroke diesel engine can benefit from LIVC with regard to fuel savings, volumetric efficiency and residual gas discharge. Similarly, Saunders R. J. [19] showed that an overall VVT approach can improve fuel economy in diesel engines. Fiorenza R. [8] concluded that a continuous VVT can increase the output torque. Caufield S. [6] reported that VVT can decrease fuel consumption in small sparkignition (SI) engines through accurate fluid path simulations. The VVT issue has been shown to be of even more benefit for auto-ignition diesel engines by Cao L. [4], who discussed its effect on gas composition and combination.

The utilization of artificial neural networks (ANNs) to anticipate the best valve event configurations has been examined by Gölcü M. [10], Bin $\mathrm{Wu}[2]$ and Khaldoun K. [14]. These studies lack proper modeling and insist on using experimental data to train the ANNs, which is expensive and may be unreliable.

While a considerable number of studies have addressed VVT, nearly all have concentrated on physical simulations. Mathematical modeling of engine-cylinder behavior is difficult to obtain; thus, for all the studies, the results are experimental with almost no mathematical basis. This 
makes the task of studying cylinder behavior for the full range of valve events difficult and expensive to achieve. The current study formulated pressure production inside a cylinder and used optimization techniques to observe and anticipate possible changes due to VVT.

\section{CURRENT WORK}

\section{Cylinder Pressure Formulation}

Three timing diagrams (inlet valve, outlet valve and piston position) are required to study cylinder events as independent events and to give cylinder pressure and piston operation as outputs. Traditionally, the camshaft rotates twice per crankshaft cycle, beginning from the zero angle $\theta_{0}$ when the piston is in the fully-folded position and there is virtually no gas remaining inside the cylinder.

The crankshaft rotates at speed $\omega$ and causes the piston to move; this speed is assumed to be constant for two rounds. The effect of valve operation is on the gas inlet-outlet through the opened pathway. The pressure difference through a passage between two containers can be formulated as:

$$
M_{F}=R(\theta) \Delta P
$$

where: $R$ is the passage reluctance depending on valve motion.

The cylinder pressure varies according to the relocated fluid mass and piston location; thus, some of the smaller effects could be delayed. The cylinder capacity changes as the piston moves according to:

$$
V_{c y l}=x_{p i s} S_{p i s}=\alpha \cos \theta+\beta \cos 2 \theta+C=V(\omega t)
$$

According to Boyle's law, if no thermal event has occurred, the volume-pressure product remains constant. Volume as a variable only depends on crankshaft speed while pressure is related to volume, valve events and combustion. Because valve events occur within a short angle span during crankshaft rotation, the effect of a change in volume on the imported fuel mass can be neglected, and it is assumed to be dependent only upon the valve event according to:

$$
M_{\text {Fuel }}=R(\theta) \Delta P
$$

where: $R$ is a factor which can be determined experimentally, but can also be modelled as a factor of a sinusoidal function dependent upon the main shaft angle and cylinder pressure.

The inlet fuel mass varies exponentially, but in reverse quantities. The IVC event occurs at $\theta_{1}$ if the ignition instant corresponds to $\theta_{2}$ and the cylinder pressure between the IVC and ignition depends only on the volume. At the moment of ignition, the pressure dramatically increases as the volume and ignited fuel mass increase. Some studies have used a differential equation for the consumption of the fuel mass as reported in an article by Osama H. [16]:

$$
M_{i g}=M_{\text {fuel }}\left(1-\exp \left(-A\left(\frac{\theta}{\theta_{b}}\right)^{M+1}\right)\right)
$$

where: $\theta$ is the current angle, $\theta_{\mathrm{b}}$ is the total burn angle, and $A$ and $M$ are constants that depend upon the fuel type.

The produced pressure increases as the ignited fuel mass increases, but decreases as the volume increases.

$$
P_{c y l}=C M_{i g}=C M_{f u e l}\left(\exp \left(A\left(\frac{\theta}{\theta_{b}}\right)^{M+1}\right)\right)
$$

After combustion, EVO occurs when the system is designed under conditions approaching those described in Eq. (1). If the exhaust is delayed too long, the pressure difference between the exhaust chamber and the cylinder may decrease such that much work would be required to pump out the emissions. If it occurs too early, some of the work from combustion may be wasted. Some studies suggest that if the IVO event occurs concurrently with the EVO, this could aid emissions, but it is not possible to predict the quantity of fuel injected with such accuracy.

The overview of cylinder events makes it possible to describe the cylinder pressure and volume for valve event timing and the work extracted. Subsequently, the cylinder pressure for the full range of the valve event timing is examined. The philosophy behind this strategy is that the proportional pressure 
inside the cylinder for either the fuel rail or the exhaust chamber determines whether the cylinder can absorb energy or must be fed work in the suction or exhaust phases; thus, the pressure parameter must be identified and simulated. After resolving the rule describing differential equations with acceptable precision, the cylinder pressure behaviour can be modelled as:

$$
\left\{\begin{array}{c}
P_{c y . I V O-I V C}=P_{\text {fuel rail }} R(\theta)\left(1-e^{-\theta}\right) / V(\theta) \\
P_{c y I V C-\theta 1}=P_{c y I V C} / V(\theta) \\
P_{c y . i g .}=A P_{c y 1} e^{B\left(\frac{\theta}{\theta_{b}}\right)^{M+1}} \\
P_{c y \theta b-E V O}=P_{c y \theta b} / V(\theta) \\
P_{c y . E V O-E V C}=\left(P_{c y 2} R(\theta) e^{-\theta}-P_{a t m .} R(\theta)\left(1-e^{-\theta}\right)\right) / V(\theta)
\end{array}\right.
$$

where: $\mathrm{AP}_{\text {cyl }}$ is the fuel mass allocated during the IVO event. It is assumed that the effect of changes in cylinder volume is negligible during the ignition phase because the ignition effect is dominant. This effect is modelled as $\mathrm{V}(\theta)$ during valve events where $\mathrm{PV}=$ fluid energy.

There are two major considerations with respect to the events. The first is that the valve events are considered to be independent of crankshaft rotation; at any given moment, however, the cylinder pressure can be affected by this parameter. The second is that the piston stroke concurrent with the cylinder pressure can indicate whether or not the piston can yield energy from the pressure. Because the piston motion is necessarily independent of the valve events, a strategy could be developed to formulate them all. This has seldom been a feature of previous studies. Although valve events are independent, the instant of ignition is always at the TDC.

\section{Model Verification}

Before suggesting improvements, the current modelling approach must be verified by comparing the results of simulations with physical sensory measurements and with the results of the mathematical calculations. Application of the equations in a programming environment allowed comparison of the results with those of other studies, such as the thesis of Chedthawut P. [7]. It was concluded that the proposed model is quite accurate for the parameters tested, although in nearly all other research cylinder pressure was introduced as the only practicably measurable

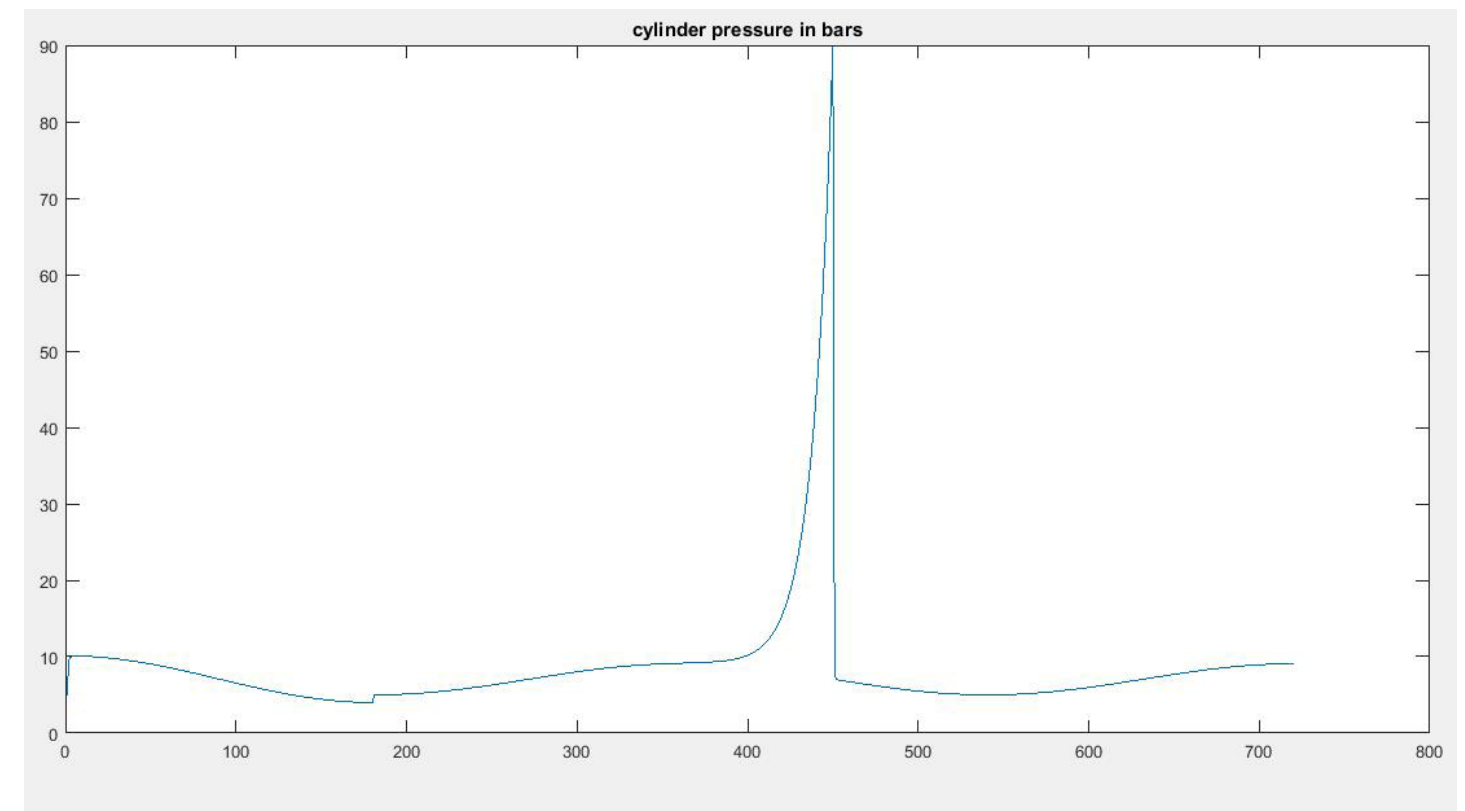

Fig. 2. An overview of the cylinder pressure where IVC occurs at 0 degree, EVC at 540 degree and ignition at 360 degrees, identical to the results of actual experimental sensory data 


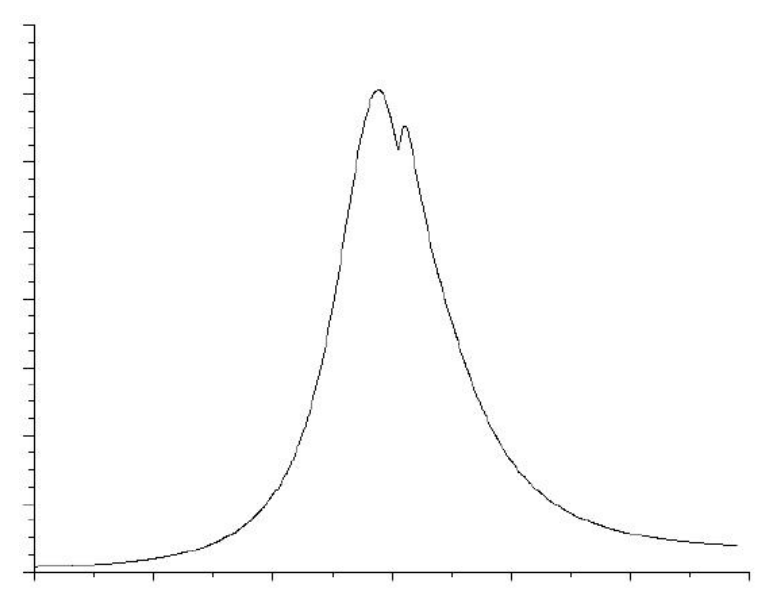

Fig. 3. The cylinder pressure at a cycle with only assuming the ignition event and denying the valve events to be effective, obtained from the simulation based upon the eddy dissipation

value and was not thought to be predictable. A simulation program should be developed to cover the overlap between valve events by summing the effects, as is done for the effect of cylinder volume as an external independent variable. The predicted cylinder pressure under conditions similar to those in the previously-mentioned thesis is shown in Figure 2.

A cylinder pressure simulation is required in which the ignition-combustion pressure is physically simulated. For this purpose, a model was developed in ANSYS Fluent that is based upon the eddy dissipation model by Bjørn F. [3]. For most flammable admixtures, ignition proceeds rapidly and is only controllable by the manipulation of the mixture ratios. Such mixing limits combustion so that the chemical reaction time is scalable (eddy dissipation) and combustion oc-

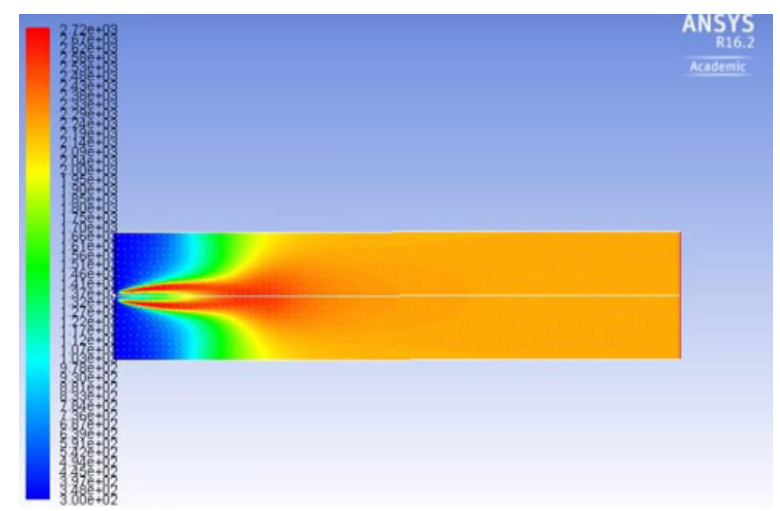

Fig. 4. Temperature-Pressure distribution inside a cylinder at the ignition instance

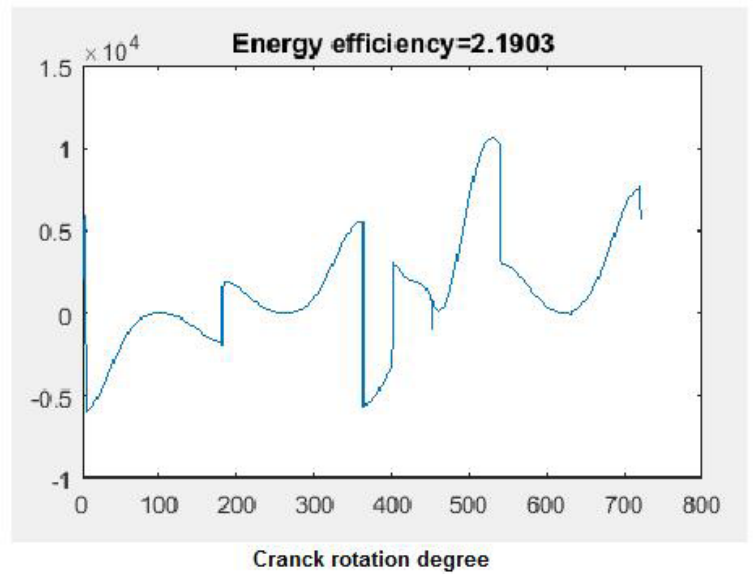

Fig. 5. Cylinder energy graph (in Joules) and its efficiency at the initial speed and valve events state

curs whenever turbulence occurs in the flow. No source of ignition is required if the turbulence can create sufficient temperatures to initiate combustion. These ignition events can be simulated with smaller timescales when comprehensively studied using the eddy dissipation method.

In the proposed simulation, the valve events are not summed over the full cylinder cycle. The results show only the combustion-phase pressure where ignition occurs at the TDC. This feature is common to both SI and diesel engines as it is assumed that the spark only occurs at the TDC. The current simulation results for pressure at the piston surface are shown in Figure 3. One could safely presume that the application of valve event factors could alter the graph to make it similar to that shown in Figure 2. Figure 4 shows the graphical results for the final moment of the cylinder ignition simulation.

\section{Full-range VVT Effects}

Using the information obtained thus far makes it possible to study the effects of the full range of VVTs for combustion efficiency by comparing the generated pressure and volume with piston motion data. If the pressure increases as the volume increases, kinetic energy is being absorbed from the cylinder event. If the volume decreases as the pressure increases, the energy is being absorbed by the cylinder event. A volume-pressure graph can track the energy events in the cylinder. The effect of valve timing at different crankshaft speeds can be studied. In order to avoid depiction of the demographic images of the two parameters for each event and crankshaft speed setup, a cylinder efficiency parameter must be defined as: 
$\delta=\frac{\text { cylinder produced energy at } 720 \text { degrees }}{\text { cylinder consumed energy at } 720 \text { degrees }}$

where: the energy is in proportion to the differential sign of the volume and pressure applied to the multiplication of the parameters themselves.

The efficiency parameters measured under the conditions shown in Figure 2, are depicted in Figure 5. Now that the quality has been ensured, the following Simulink diagram is proposed, and crankshaft rotation speed changes are applied in Figure 6. The crankshaft speed angle was also applied in MATLAB Simulink. The output work is calculable as follows with respect to the force-displacement profile enforced for the piston: $\mathrm{W}=\mathrm{FR}$.

A common four-stroke four-cylinder engine can operate at crankshaft speeds of up to 50 rounds per second $(3,000 \mathrm{rpm})$, where two cycles execute a complete cylinder action set. To investigate the full effects, the input rotation speed can be varied in the range 1-50 rounds per second, the IVO between $0^{\circ}$ and $90^{\circ}$, the IVC between $90^{\circ}$ and $180^{\circ}$, the EVO between $540^{\circ}$ and $630^{\circ}$ and the EVC between $630^{\circ}$ and $720^{\circ}$. The ignition point is considered to be constant at $360^{\circ}$ and the total ignition angle at $540^{\circ}$ (power stroke).

\section{RESULTS AND CONCLUSIONS}

It is only necessary to vary the valve events at each crankshaft speed and record the cylinder efficiency for each set. Table 1 shows the best conditions for a cylinder resulting in the highest efficiency rate. The variables are changed using 10 crank-angle steps. Such a set of data can be used to determine the required valve event angles in order to optimize cylinder efficiency with respect to crankshaft speed by calculating the mean values for two columns of the table, repeating the simulation or using a trained prediction algorithm like ANN. Further investigations could test an actual internal combustion engine using all necessary instruments.

All other parameters were kept constant. The calculations are performed at full load conditions. It shows a decrease in power with the (EVO) angle reduction for all engine running speeds. But it is less sever at lower engine speed (less than $1500 \mathrm{rpm})$. At low speeds, a late (EVO) reduce the volumetric efficiency. But in contrast at high engine speeds, early (EVO) leads to greater reduction in volumetric efficiency and it causes a limitation in the output power. This is due to the less effective scavenging of the cylinder, as the pressure decreases. Power is drawn versus the EVC angle for different engine speeds between (1000 -

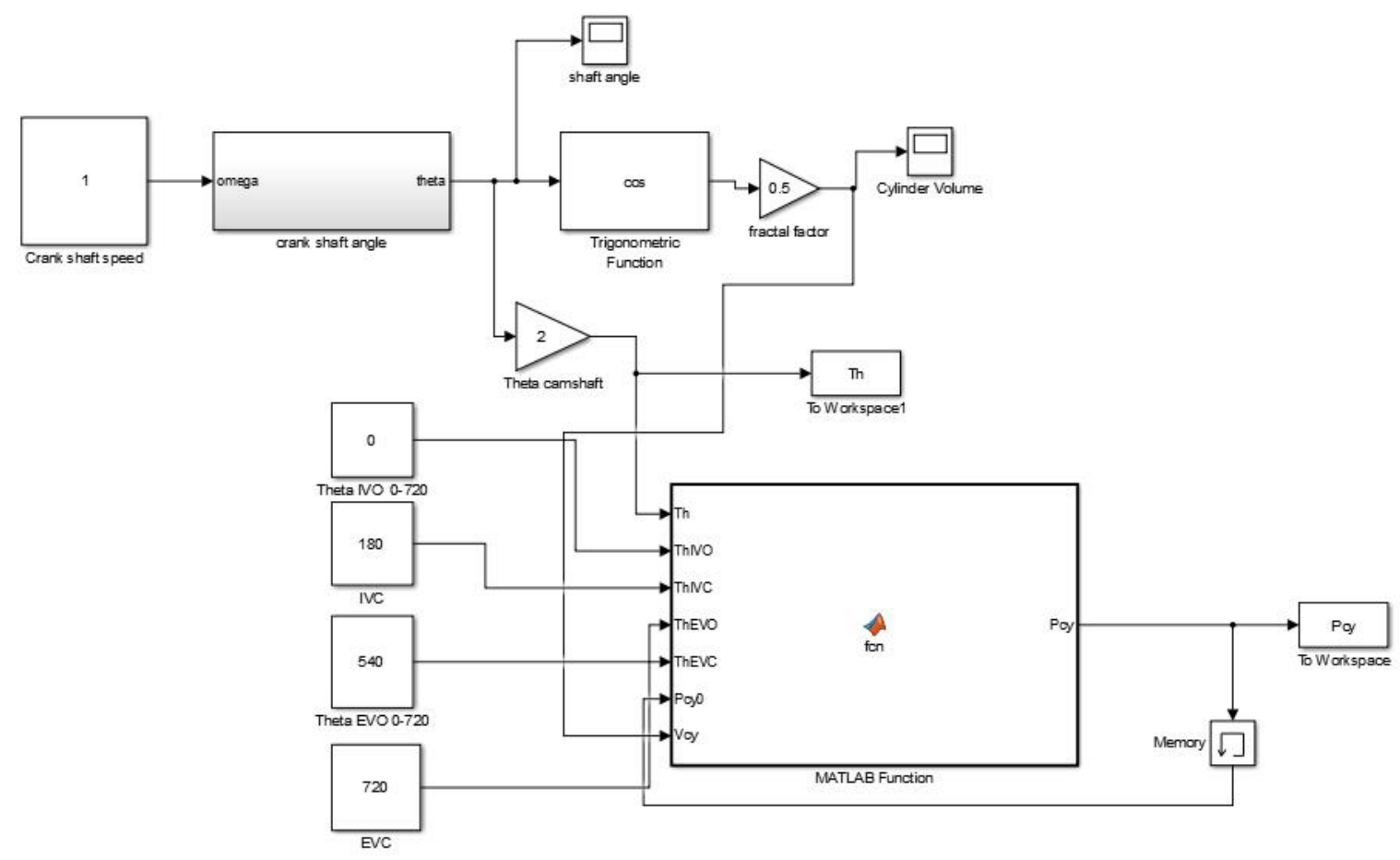

Fig. 6. SIMULINK structure with variable crank shaft speed and valve timing inputs 
$5000 \mathrm{rpm})$. It shows an increase in power with the (EVC) angle reduction but this increase in power was small for values of (EVC) less than $25^{\circ}$ for all engine running speeds considered. This effect is more recognized at higher engine speeds (2500$5000 \mathrm{rpm}$ ). The increase in power may be due to the reduction of residual gases and backflow of exhaust into the inlet manifold, but a late (EVC) closing causes the high pressure exhaust gas reducing the amount of inlet mixture incoming through the inlet manifold. A retarded valve close angles creates a considerable reverse flow and results in the reduction of cylinder's volume effectiveness and internal exhaust gas recirculation.

The presented investigation has provided a suitable modeling approach to simulate cylinder volume-pressure profiles and thus avoid the expensive experimental tests suggested in previous studies. The proposed model anticipates engine behavior and cylinder productivity at variable speeds and different arrangements of valve event angles. The results table indicates that as shaft rotation speed increases, earlier IVO overlap with EVC could improve cylinder efficiency, and earlier IVC is needed to improve fuel mass compression inside the cylinder. At the same time, late EVO is desirable to prevent loss of ignition energy. Apparently, as the engine speed increases, lower efficiency rates are retrievable

These results can be used to establish a VVT lookup table for the designs for which independent valve actuators are available. It is also possible to use the data to create and train an artificial neural network matrix to predict the most suitable valve event angles with respect to engine output speed, utilizing its regression feature. In addition, because the moment of ignition is assumed to be constant at the TDC point, testing will be reliable for both SI and diesel four-stroke engines.

This work has not yet considered parameters such as variable fuel rail pressures and fuel admixture, insufficient combustion procedures or the effect of the possible remaining exhaust gas inside the cylinder, because there are almost no comprehensive simulation environments available which could cover all the elements. Furthermore, providing such a thorough formulation will require extensive testing instruments to verify the model, and other approaches could be assumed to be as effective.

The contribution of the final strategy in this scheme, refer to engines with one exhaust and one inlet camshaft each. Engines with more than one exhaust and one inlet camshaft require a Hall sender and a valve for camshaft adjustment for each camshaft.

\section{REFERENCES}

1. Benson, R.S., Annand, J. D. and Baruah, P.C., A simulation Model Including Intake and Exhaust Systems for a Single Cylinder Four-Stroke Cycle Spark Ignition Engine, Int. J. Mech. Sci, Pergamon Press, 17, 1975, 97-124.

2. Bin $\mathrm{Wu}$, Using artificial neural networks for representing the air flow rate through a 2.4 liter VVT engine. SAE Technical Papers. Powertrain and Fluid Systems Conference and Exhibition, Tampa, FL, United States, 25-28 October.

3. Bjørn F. Magnussen, The Eddy Dissipation Concept A Bridge Between Science And Technology ECCOMAS Thematic Conference on Computational Combustion, Lisbon, June 21-24, 2005.

4. Cao L., Zhao H., Jiang X. and Kalian N., Understanding the Influence of Valve Timings on Controlled Auto-Ignition Combustion in a Four-Stroke Port Fuel Injection Engine. Journal of Automobile Engineering, 6 (219), 2005, 807-823.

5. Carrie M. Hall, Combustion Phasing Model for Control of a Gasoline-Ethanol Fueled SI Engine with Variable Valve Timing, American Control Conference Fairmont Queen Elizabeth, Montréal, Canada June 27-June 29, 2012.

6. Caufield S, Rubenstein B, Martin JK, et al. A comparison between CFD predictions and measurements at inlet port discharge coefficient and flow characteristics. In: SAE Paper No. 1999-01-3339 in the small engine technology conference and exposition; 1999.

7. Chedthawut Poompipatpong, Effects Of Intake Valve Timing And Injection Timing In A Natural Gas Dedicated Diesel Engine. Msc Final Thesis, King Mongkut's Institute Of Technology North Bangkok Academic Year 2007.

8. Fiorenza R, Pirelli M, Torella E, et al. Variable swirl and internal EGR by VVT application on small displacement 2 valve SI engines: an intelligent technology combination. In: FISITA 2004 world automotive congress. May 23-27.

9. Fontana G., Galloni E., Variable valve timing for fuel economy improvement in a small spark-ignition engine. Elsevier Journal of Applied Energy 86, 2009, 96-105.

10. Gölcü M., Artificial neural-network based modeling of variable valve-timing in a spark-ignition engine. Elsevier Journal of Applied Energy, 2 (81), 2005, 187-197.

11. Hara S, Nakajima Y, Nagumo S., Effects of intake valve closing timing on SI engine combustion, In: SAE Technical Paper Series 850074; 2015. 
12. Joonsup Han, Jaehyeon Lee, Hyungmin Kim, Kihyung Lee, A Study on the Effect of Valve Timing on the Combustion and Emission Characteristics for a 4-cylinder PCCI Diesel Engine. World Academy of Science, Engineering and Technology International Journal of Mechanical, Aerospace, Industrial, Mechatronic and Manufacturing Engineering, 10 (4), 2010.

13. Kang, J.Mo. and Grizzle, J.W. Dynamic control of a SI engine with variable intake valve timing. International Journal of Robust and Nonlinear Control, 5 (13), 2003, 399-420.

14. Khaldoun K. Tahboub, An ANN-GA Framework for Optimal Engine Modeling. Mathematical Problems in Engineering, vol. 2016, Article ID 6180758, 8 pages, 2016. doi:10.1155/2016/6180758.

15. Luria D., Taitel Y., And Stotter, A., The Otto-Atkinson Engine anew Concept in Automotive Economy. SAE paper 820352, 2002.

16. Osama H. M. Ghazal, Modeling the Effect of Variable Timing of the Exhaust Valves on SI Engine
Emissions for Greener Vehicles", SCIRP journal of Energy and Power Engineering, 5, 2013, 181-189.

17. Paulina S. Kuo, Cylinder Pressure in a Spark-Ignition Engine: A Computational Model", J. Undergrad. Sci. 3, 1996, 141-145.

18. Rabia S. M., Effect Of Valve Timing And Exhaust Back Pressure On The Performance Of Gasoline Engine, Journal of Engineering Sciences, Assiut University, 3 (38), 2010, 685-696.

19. Saunders, R.J., And Rabia, S.M., Part Load Efficiency in Gasoline Engines, paper presented at Institution of Mechanical Engineers, Combustion Engines Group, 1986.

20. Tuttle JH, Controlling engine load by means of late intake-valve closing, In: SAE paper No. 800794 in the automotive engineering congress and exposition; 2008.

21. Wu C., Puzinauskas P.V., Tsai JS. Performances analysis and optimization of a supercharged Miller cycle Otto engine. Appl Therm Eng 23, 2013; 511-21. 